\title{
Wear Rate vs Dynamic and Material Properties at Elevated Temperatures for a Copper-Graphite Brush
}

\author{
Aleš Turel $^{1}$ - Janko Slavič ${ }^{2}-$ Miha Boltežar $^{2}$ \\ ${ }^{1}$ Mahle Letrika d.o.o., Slovenia \\ ${ }^{2}$ University of Ljubljana, Faculty of Mechanical Engineering, Slovenia
}

A copper-graphite brush is used as a sliding part in the electrical contacts of electrical machines and usually operates at elevated temperatures. This experimental research relates the dynamic properties of the copper-graphite brush to its wear rate at elevated temperatures. The dynamic and material properties were researched using a dynamic response analysis, hardness test and differential scanning calorimetry. The results show that there is a key temperature range where the material properties of copper-graphite brush was changed and which reflects on the increases of damping by $15 \%$ and hardness decreases by $50 \%$.

Keywords: electrical contacts, thermal effects, dynamic analysis, sliding wear

Highlights
- Dynamic and material properties at elevated temperatures for copper-graphite brush were researched.
- Wear rate, dynamic response analysis and material properties were compared.
- By hysteretic damping ratio the crucial temperatures (at $80^{\circ} \mathrm{C}$ and $180^{\circ} \mathrm{C}$ ) of copper-graphite brush material was observed.
- In narrow brush temperature range, between $80^{\circ} \mathrm{C}$ and $90^{\circ} \mathrm{C}$ an increase of damping was observed.

0 INTRODUCTION

Sliding electrical contacts are necessary whenever an electrical current needs to be transferred between a stationary and a rotating part, like in alternators or DC motors. A brush and a slip-ring or commutator, which form the contact, are the primary components that affect the lifetime of electrical machines. Therefore, a lot of attention has been given to the prediction of wear in electrical contacts [1] to [3]. The influence on the wear rate has been investigated for the sliding speed [4] to [6], electrical current [7] to [9], ambient conditions [10] and [11], contact pressure [5], [8] and [12] and material properties [13] to [15] of a brush. In addition to the mentioned parameters, attention has also been given to the dynamics of the brush through the coefficient of friction [16], brush stability [17] and vibrations [18] to [21].

The wear rate and dynamics of a copper-graphite brush are highly dependent on the properties of the brush material [1]. The material properties can be researched by differential thermal analysis (DTA) or by thermogravimetric (TG) analyses, e.g., Kuz'mina et al. [22]. They observed that an increase in the copper content in the composite leads to a change in the shape of the TG curves, while the binder properties, an ordinary compound of the brush composite, can be tested with differential scanning calorimetry (DSC)
[23]. In addition to the DSC analyses, the material properties were also studied using hardness tests [24].

The effect of temperature on the dynamic properties of the brush is not commonly referred to as an influencing wear parameter, and only a few studies have paid attention to these properties separately [17], [20], [22] and [25].

The aim of this study was to analyse the effect of temperature on the dynamic properties of the copper-graphite brush and to compare it to the wear rate. The dynamic properties were investigated through the natural frequencies, the hysteretic damping ratio and evaluated through the material's properties, i.e., hardness tests and DSC, while the wear rate was measured previously, see, e.g., [26].

This research is organised as follows: in Section 1 the experimental methodology is introduced, in Section 2 the experimental results with a discussion are presented, and in Section 3 the conclusions are given.

\section{EXPERIMENTAL RESEARCH}

In the experimental research section the methods and conditions for the dynamic response analyses, DSC, hardness and wear rate are presented. The dynamic properties were researched using dynamic response analyses, compared to the wear rate of the copper-graphite brush. For an additional insight into the effect of temperature on the brush material's 
properties, hardness tests and DSC analyses were performed.

\subsection{Dynamic Response Analyses}

The dynamic response analyses were performed to evaluate the influence of the temperature on the dynamic properties of the copper-graphite brush. The experimental setup as shown in Fig. 1 was used, while the measurement principle is presented in Fig. 2.

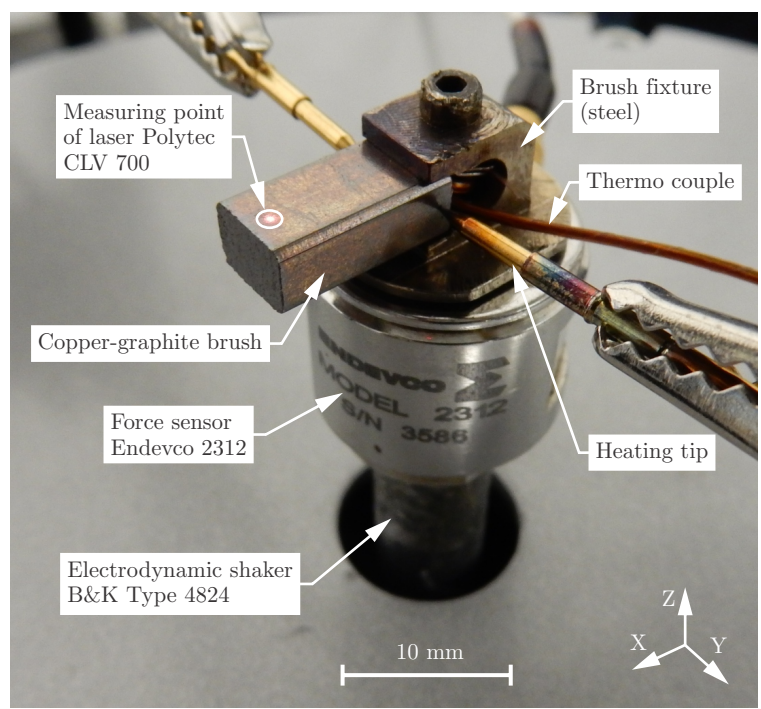

Fig. 1. Experimental set-up

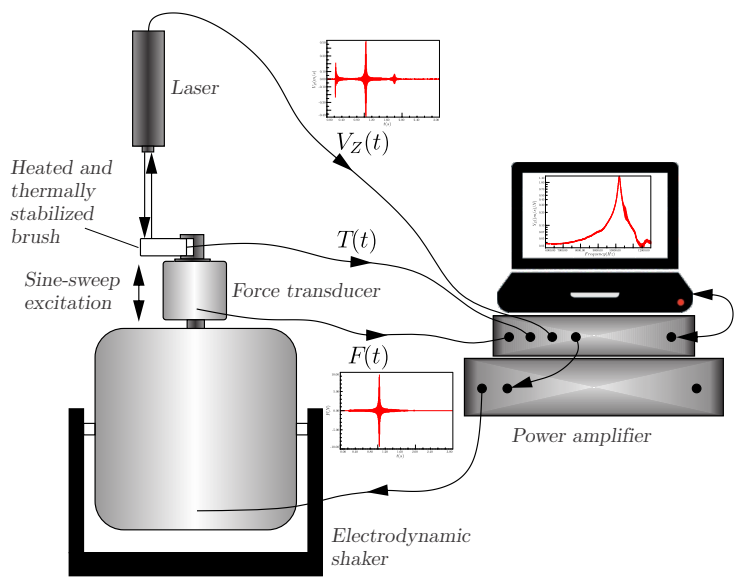

Fig. 2. Measurement principle

The force sensor (Endevco 2312) with an in-line charge amplifier (PCB 422E35) was attached to the electrodynamic shaker head (Brüel \& Kjaer Type 4824) and measured the excitation force applied to the brush. The steel brush fixture with the copper-graphite brush was attached to the force sensor. As shown in Fig. 1, the copper-graphite brush was machined to a rectangular shape with dimensions of $6.4 \mathrm{~mm} \times$ $4.6 \mathrm{~mm} \times 12.0 \mathrm{~mm}$. The dynamic response of the brush was measured in the $Z$ direction using a laser vibrometer (Polytec CLV-700). The modal exciter was controlled in the open-loop mode using LMS scadas mobile.

A sine-sweep excitation from $1.0 \mathrm{kHz}$ to $21.0 \mathrm{kHz}$ was applied to the brush in the $Z$ direction. In order to measure the influence of the temperature on the dynamic response, the copper-graphite brush was Joule heated with an electrical circuit using a controlled DC power supply. The temperature applied to the brush was increased from $21^{\circ} \mathrm{C}$ to $245^{\circ} \mathrm{C}$ with a step of $1{ }^{\circ} \mathrm{C} \pm 0.5^{\circ} \mathrm{C}$. Due to the temperature stabilisation, each step took approximately $2 \mathrm{~min}$. To increase the reliability of the data, five measurements were performed at each temperature and the test (the complete temperature cycle) was repeated twice.

The measurements from the force sensor and the laser vibrometer were used to calculate the mobility $Y_{z}(\omega)[27]$ in the $Z$ axis as:

$$
Y_{z}(\omega)=\frac{V_{z}}{F},
$$

where $V_{z}$ represents the response velocity in the $Z$ direction and $F$ is the excitation force. The mobility from Eq. (1) was then calculated to give the receptance $\alpha_{z}(\omega)$ [27] by:

$$
\alpha_{z}(\omega)=\frac{1}{\mathrm{i} \omega} \frac{V_{z}}{F}=\frac{\bar{X}_{z}}{F}(\omega)=\frac{1}{\left(k-\omega^{2} m\right)+\mathrm{i} d},
$$

where $\overline{X_{z}}$ represents the complex amplitude in the $Z$ direction, $\omega$ is the frequency, $m$ is the rigid constant mass, $k$ is the constant stiffness and $d$ is the hysteretic damping coefficient. From the receptance defined in Eq. (2) the peak $\left|\alpha_{z}(\omega)\right|_{\max }$ was identified and the damping ratio $\zeta_{z}$ of the copper-graphite brush was calculated with the half power law [27], where the hysteretic damping model was used:

$$
\zeta_{z}=\frac{\omega_{2}-\omega_{1}}{\omega_{n}}
$$

where $\omega_{n}$ is the frequency at resonance, while $\omega_{2}$ and $\omega_{1}$ were the half-power frequency points, $3 \mathrm{~dB}$ below $\left|\alpha_{z}\left(\omega_{n}\right)\right|$.

\subsection{Wear Rate}

The wear rate of the dynamically excited copper-graphite brush over a wide range of operating 
conditions was reported previously [26]. The 90 tests were conducted for temperatures of the brush between $30^{\circ} \mathrm{C}$ and $120^{\circ} \mathrm{C}$. The wear rate of the brush was identified with a camera using a digital image correlation, where the initial $s_{1}$ and final $s_{2}$ positions of the brush were measured. From the known cross-section $A$, the rotational speed $v$ and the test duration $t$ the wear rate was calculated using

$$
w=\frac{s_{2}-s_{1}}{t \cdot v} \cdot A,
$$

and the temperatures of the brush were measured with an IR temperature camera.

\subsection{Hardness Test}

The measurements of the copper-graphite brush hardness were made with a hardness test device (EMCO Test - M4C 075 G3 R) according to the international standard EN ISO 6508 - Rockwell hardness test [28], where the $15 \mathrm{~T}$ scale was used.

The copper-graphite brushes were Joule heated with an electrical circuit using a controlled DC power supply. The temperature applied to the brushes was increased from $21^{\circ} \mathrm{C}$ to $140{ }^{\circ} \mathrm{C}$ with a step of $10^{\circ} \mathrm{C} \pm 1{ }^{\circ} \mathrm{C}$, while the timing for each step was the same as presented in Section 1.1. To increase the reliability of the data the hardness was measured before heating and at the stabilised temperature, where five measurements were performed at each temperature and the test (the complete temperature cycle) was repeated twice.

\subsection{Differential Scanning Calorimetry (DSC)}

DSC was performed to observe the glass-transition temperatures (TG) of the copper-graphite brush [29]. The brush was heated from $30^{\circ} \mathrm{C}$ to $300^{\circ} \mathrm{C}$ with a speed of $20^{\circ} \mathrm{C} / \mathrm{min}$ in an aluminium crucible with a nitrogen atmosphere, where the heat flow versus temperature was analysed. To increase the reliability of the data two measurements were performed and the test was repeated twice.

\subsection{Chemical Compounds of the Brush}

The chemical composition analyses were made by scanning electron microscopy (SEM - Jeol JSM-5610). The brush consists of approximately $60 \mathrm{wt} \%$ of graphite, $35 \mathrm{wt} \%$ of copper and $5 \mathrm{wt} \%$ of additives.

Every test was performed on a new brush and all the analysed brushes were from the same batch.

\section{EXPERIMENTAL RESULTS AND DISCUSSION}

The dynamic properties of the copper-graphite brush under different conditions were analysed using dynamic response analyses, as presented in Section 1.1. The receptance was calculated with Eq. (2) and presented in Fig. 3, where the effect of temperature on the natural frequency in the $Z$ direction is shown.

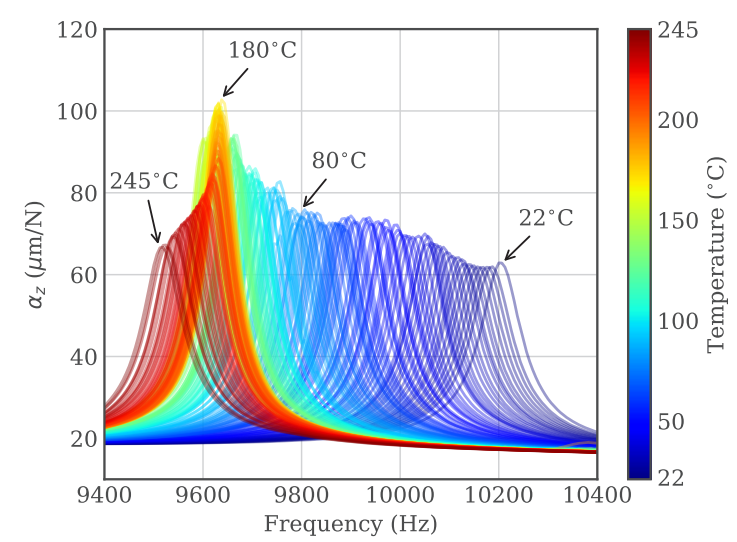

Fig. 3. Receptance $\left|\alpha_{z}\right|$ as a function of copper-graphite brush temperature

The first bending mode (around the $Y$ axis) was dominant in the excitation direction $(Z)$, see Fig. 4, where the mode was represented with a numerical simulation from ANSYS software inside the Modal analysis package. The copper-graphite brush was clamped inside a steel fixture, as in Fig. 1 (which is hidden for clarity), with a bonded connection and the material's parameter was defined by measurements, where Poisson's ratio was 0.33 and Young's Modulus was $10.1 \mathrm{GPa}$. For the first mode the highest natural frequency was observed at ambient temperature, while with increasing brush temperature the natural frequencies decreased, see Figs. 2 and 5. In the temperature ranges from $70^{\circ} \mathrm{C}$ to $90^{\circ} \mathrm{C}$ and from $150{ }^{\circ} \mathrm{C}$ to $200^{\circ} \mathrm{C}$ the changes of the dynamic response of the brush were observed, as seen in Fig. 3. For this reason the amplitude $\left(\left|\alpha_{z}\right|_{\max }\right)$ and the damping ratio $\left(\zeta_{z}\right)$ of the copper-graphite brush were analysed.

The damping ratio $\left(\zeta_{z}\right)$ of the copper-graphite brush, which is shown in Fig. 6, decreased with an increase of the temperature. With an increase of the brush temperature in the temperature range from $70^{\circ} \mathrm{C}$ to $90^{\circ} \mathrm{C}$, a sudden increase in the damping by more than $15 \%$ for all measurements was observed. 


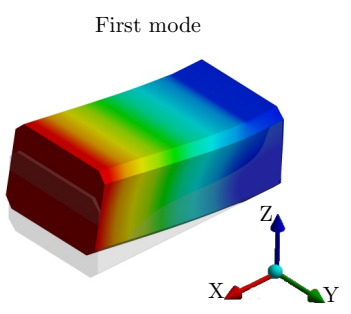

Fig. 4. First bending mode of a clamped copper-graphite brush at $22^{\circ} \mathrm{C}$ and $10200 \mathrm{~Hz}$

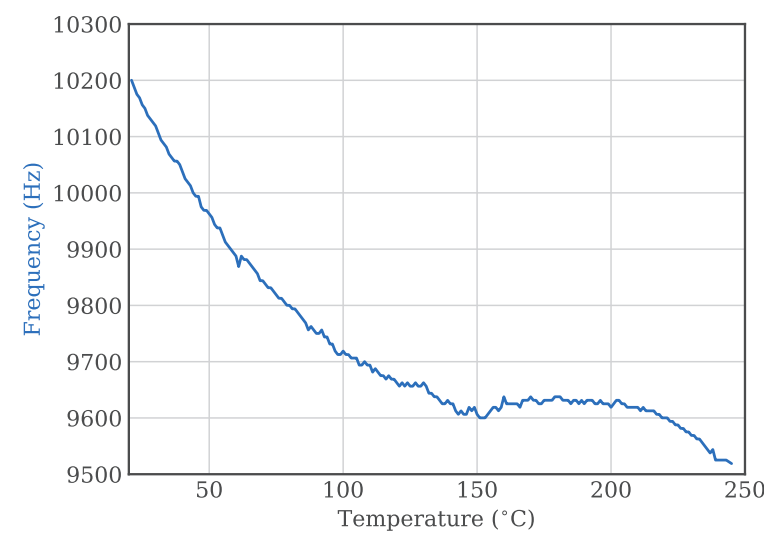

Fig. 5. First mode natural frequency as a function of copper-graphite brush temperature

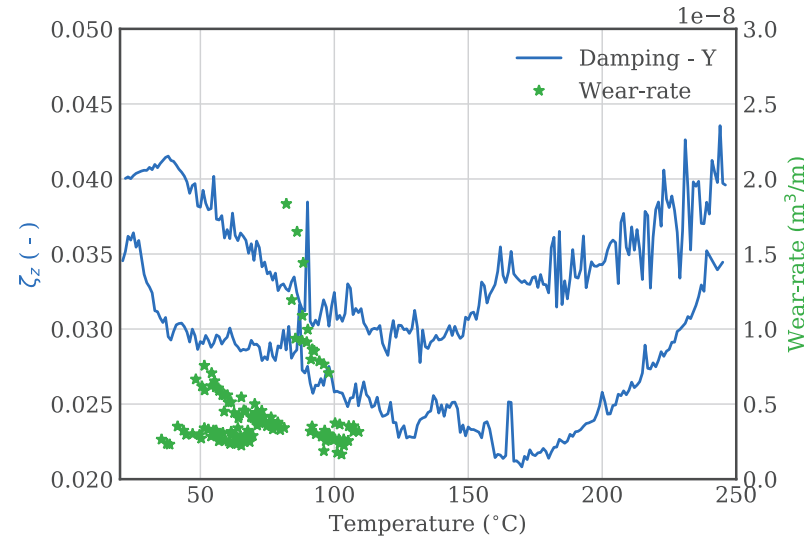

Fig. 6. Damping ratio $\left(\zeta_{z}\right)$ and wear rate as a function of the copper-graphite brush temperature

At the copper-graphite brush temperature of $90^{\circ} \mathrm{C} \pm 5^{\circ} \mathrm{C}$ an increase in the damping ratio and the wear rate was observed. As shown in Fig. 6, there is a narrow temperature range where the brush wear rate increases by up to five fold, while above that temperature the wear rate was lower and constant. Therefore, additional analyses were required.

The damping ratio and the wear rate are highly dependent on the brush material's properties [1]. For this purpose a further investigation of the brush material was made with hardness tests (Section 1.3) and DSC (Section 1.4). As presented in Section 1.5, the graphite and copper are the main components of the analysed brush. From a previous analysis of copper by DSC measurements it is known that the recrystallization temperature is at $170{ }^{\circ} \mathrm{C}$ [30]. Furthermore, the brush also contains additives, which change the material properties. Kuz'mina et al. [22] observed the beginning of the pitch degradation of copper-graphite composites at $75^{\circ} \mathrm{C}$. They also observed the absence of moisture above $100^{\circ} \mathrm{C}$.

For the brush material the DSC analysis were carried out with two heating phases. The DSC curve presented in Fig. 7 presents first heating with the endothermic peak at $80^{\circ} \mathrm{C}$ and exothermic peak at $180^{\circ} \mathrm{C}$. During the heating from $30^{\circ} \mathrm{C}$ to $300^{\circ} \mathrm{C}$ a polymerisation of the brush material in the temperature range from $80^{\circ} \mathrm{C}$ to $270^{\circ} \mathrm{C}$ was observed. At the beginning of the polymerisation, an endothermic peak was present, which can be attributed to removal of moisture and to actions of additives. The additives of copper-graphite brush mostly consist of phenolic resin. At that temperature the resin molecules have restricted mobility [23]. Exothermic peak at $180^{\circ} \mathrm{C}$ corresponds to polymerisation peak temperature which is more distinct and at the same temperature as minimum of damping ratio. Therefore the relation between damping ratio $\left(\zeta_{z}\right)$ and DSC is presented in Fig. 8. After the beginning of the polymerisation the material properties of the brush changes significantly. The damping ratio decreases rapidly up to polymerisation maximum temperature.

After the first heating phase the brush material completely polymerised.

The wear behaviour of the sliding contacts is normally calculated using the Holm-Archard law, as shown in Eq. (5) [31] and [32]:

$$
V_{\text {wear }}=k \cdot \frac{F_{N} \cdot g_{T}}{H},
$$

where $V_{\text {wear }}$ is the wear volume, $k$ is the wear coefficient, deduced from the experimental data, $F_{N}$ is the normal force, $g_{T}$ is the relative sliding distance between the materials and $H$ denotes the hardness, which is equal to the mean contact pressure of the surface that is worn away [32]. 


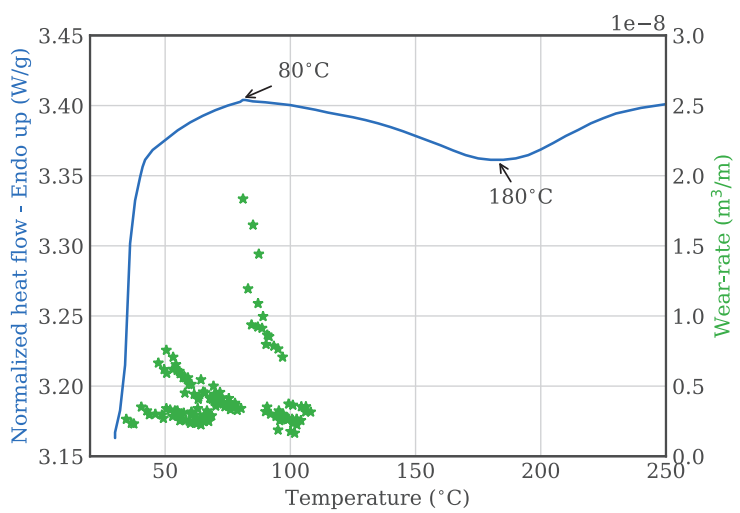

Fig. 7. DSC analysis and wear rate as a function of the copper-graphite brush temperature

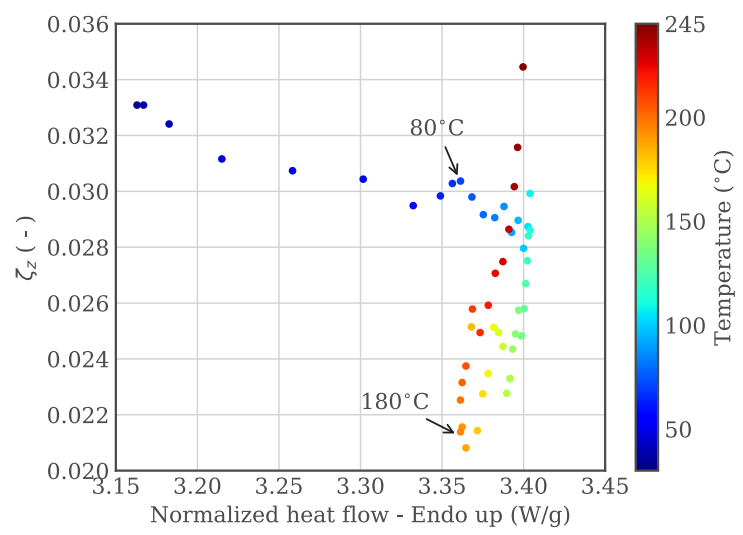

Fig. 8. Damping ratio $\left(\zeta_{z}\right)$ vs DSC as a function of the copper-graphite brush temperature

Therefore, hardness measurements of the copper-graphite brush were performed. From the hardness measurements shown in Fig. 9 a decrease in the hardness up to $50 \%$, in a narrow temperature range from $80^{\circ} \mathrm{C}$ to $90^{\circ} \mathrm{C}$, was observed. In this temperature range large deviations of the hardness measurements were observed (ten measurements at each temperature - inside shaded regions). This deviations are related to the spread in the brush material's composition. Because the brush is manufactured with a sintering process there are small deviations in the composition, i.e., the portion of phenolic resin in the brush or the porosity of each sample [33] and [34]. The porosity of the sample also depends on the portion and distribution of the moisture in the brush sample. In this temperature range the majority of the moisture is removed from the brush material [22]. The removal of moisture from the copper-graphite brush material leads to more free space in the pores, which makes the brush softer and accelerates the oxidation process of the copper, which also leads to deviations in the hardness between the samples. At higher temperatures the brush is out of moisture. The hardness results confirm that the copper-graphite brush became softer at $80^{\circ} \mathrm{C}$ to $90^{\circ} \mathrm{C}$, which reflects in the damping ratio and the wear rate.

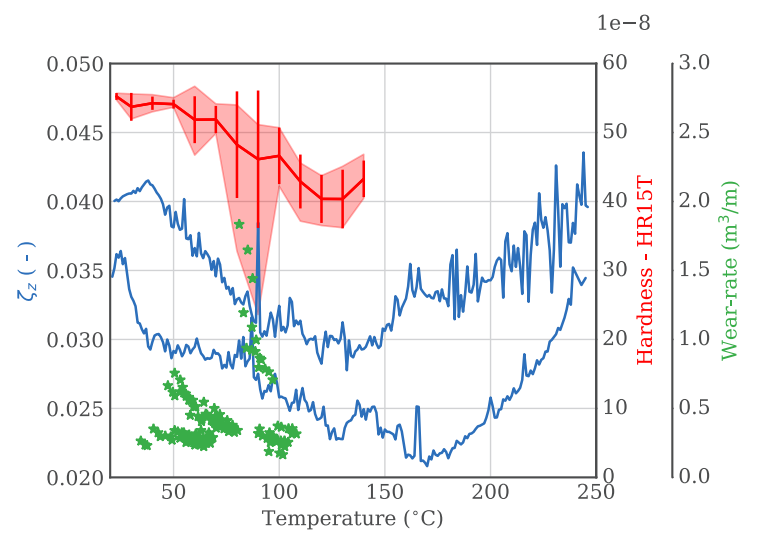

Fig. 9. Damping ratio $\left(\zeta_{z}\right)$, wear rate and hardness as a function of the copper-graphite brush temperature

At $80^{\circ} \mathrm{C}$ the phenolic resin, which is the main additive in the copper-graphite brush, has restricted the mobility of the resin molecules [23]. Consequently, the combination of resin and moisture phenomena affect the wear rate, Fig. 10.

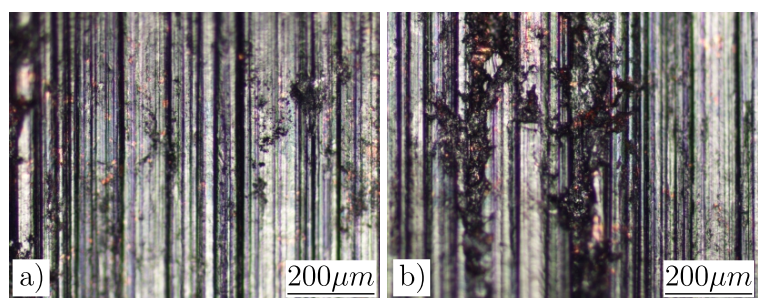

Fig. 10. Optical images of the worn contact surfaces of the copper-graphite brush: a) at $100^{\circ} \mathrm{C}$ and b) at $85^{\circ} \mathrm{C}$

An increase in the hysteretic damping ratio was observed at $80^{\circ} \mathrm{C}$. This increase is related to the material properties of the copper-graphite brush. The brush became softer at that temperature, which was confirmed by the hardness measurements. From the hardness, DSC and damping-ratio analyses we found that the temperature has a crucial effect on the brush 
material's properties, which also reflects on the wear rate.

\section{CONCLUSIONS}

The temperature's influence on the dynamic properties like the hysteretic damping ratio $\left(\zeta_{z}\right)$ of the copper-graphite brush compared to wear rate was analysed. At $80^{\circ} \mathrm{C}$ the sudden increase of damping by more than $15 \%$ was observed. The sudden increase of damping is connected to changes in the copper-graphite brush material properties. At this temperature it was found that the endothermic peak was present, the polymerisation of copper-graphite brush was started and the brush become softer. It's hardness decreased by $50 \%$. At the temperature range of $80^{\circ} \mathrm{C}$ to $90^{\circ} \mathrm{C}$ the moisture removes from the brush material which softer brush and accelerate oxidation. In the narrow temperature range $90^{\circ} \mathrm{C} \pm 5^{\circ} \mathrm{C}$ the copper-graphite brush is softer and has additives which has restricted mobility of the resin molecules [23] at that temperature an increase of wear rate up to a five-fold was observed.

This research shows that the wear rate at increased temperature relates to the dynamic and material properties.

\section{FUNDING}

The authors acknowledge the partial financial support from the research project EVA4Green.

\section{REFERENCES}

[1] Slade, P.G. (2013). Electrical Contacts: Principles and Applications, 2nd ed., CRC Press, Boca Raton.

[2] Rajkumar, K. Kundu, K., Aravindan, S., Kulkarni, M.S. (2011). Accelerated wear testing for evaluating the life characteristics of copper-graphite tribological composite. Materials \& Design, vol. 32, no. 5, p. 3029-3035, D0l:10.1016/j. matdes.2011.01.046.

[3] Benedik, B., Taškova, K., Tavčar, J., Duhovnik, J. (2015). Prediction of vacuum cleaner motor brush life: a regression approach. IET Electric Power Applications, vol. 9, no. 9, p. 569-577, D0I:10.1049/iet-epa.2014.0437.

[4] Bouchoucha, A., Chekroud, S., Paulmier, D. (2004). Influence of the electrical sliding speed on friction and wear processes in an electrical contact copper-stainless steel. Applied Surface Science, vol. 223, no. 4, p. 330-342, D0l:10.1016/j. apsusc.2003.09.018.

[5] Shin, W.-G., Lee, S.-H. (2010). An analysis of the main factors on the wear of brushes for automotive small brush-type DC motor. Journal of Mechanical Science and Technology, vol. 24, no. 1, p. 37-41, D0l:10.1007/s12206-009-1135-4.

[6] Sawa,, K., Isato, M., Ueno, T., Nakano, K., Kondo, K. (2017). Commutation characteristics and brush wear of $d c$ motor at high rotation speed. 2017 IEEE Holm Conference on Electrical Contacts, p- 176-181, DOl:10.1109/HOLM.2017.8088082.

[7] Bares,, J.A., Argibay, N., Mauntler, N., Dudder, G.J., Perry, S.S., Bourne, G.R., Sawyer, W.G. (2009). High current density copper-on-copper sliding electrical contacts at low sliding velocities. Wear, vol. 267, no. 1-4, p. 417-424, D0l:10.1016/j. wear.2008.12.062.

[8] Grandin, M., Wiklund, U. (2013). Friction, wear and tribofilm formation on electrical contact materials in reciprocating sliding against silver-graphite. Wear, vol. 302, no. 1-2, p. 1481-1491, Dol:10.1016/J.wear.2013.02.007.

[9] Grandin, M., Wiklund, U. (2018). Influence of mechanical and electrical load on a copper/copper-graphite sliding electrical contact. Tribology International, vol. 121, p. 1-9, DOI:10.1016/j.triboint.2018.01.004.

[10] Wu, J., Li, J., Zhang, L., Qian, Z. (2017). Effects of environment on dry sliding wear behavior of silver-copper based composites containing tungsten disulfide. Transactions of Nonferrous Metals Society of China, vol. 27, no. 10, p. 22022213, DOI:10.1016/S1003-6326(17)60246-2.

[11] Chen, F., Feng, Y., Shao, H., Zhang, X., Chen, J., Chen, N. (2012). Friction and wear behaviors of Ag/MoS2/G composite in different atmospheres and at different temperatures. Tribology Letters, vol. 47, no. 1, p. 139-148, Dol:10.1007/ s11249-012-9970-3.

[12] Yasar, I., Canakci, A., Arslan, F. (2007). The effect of brush spring pressure on the wear behaviour of copper-graphite brushes with electrical current. Tribology International, vol. 40, no. 9, p. 1381-1386, D0I:10.1016/j.triboint.2007.03.005.

[13] Samal, C.P., Parihar, J.S., Chaira, D. (2013). The effect of milling and sintering techniques on mechanical properties of Cu-graphite metal matrix composite prepared by powder metallurgy route. Journal of Alloys and Compounds, vol. 569, p. 95-101, D0I:10.1016/j.jallcom.2013.03.122.

[14] Klement, M., Lott, O., A. Nagel, A. (2014). Synthesis and tribo-electric characterization of copper-graphite-composites with interpenetrating microstructure for sliding contacts. Proceedings of the 27th International Conference on Electrical Contacts, p. 1-5.

[15] Wang, P., Zhang, H., Yin, J., Xiong, X., Tan, C., Deng, C., Yan, Z. (2017). Wear and friction behaviours of copper mesh and flaky graphite-modified carbon/carbon composite for sliding contact material under electric current. Wear, vol.380-381, p. 59-65, D0I:10.1016/j.wear.2017.02.045.

[16] Slavič, J., Boltežar, M. (2006). Simulating multibody dynamics with rough contact surfaces and run-in wear. Nonlinear Dynamics, vol. 45, no. 3-4, p. 353-365, D0l:10.1007/s11071005-9012-x.

[17] Slavič, J., Nastran, M., Boltežar, M. (2006). Modeling and analyzing the dynamics of an electric-motor brush. Strojniški vestnik - Journal of Mechanical Engineering, vol. 52, no. 2, p. 126-137.

[18] Slavič, J., Bryant, M.D., Boltežar, M. (2007). A new approach to roughness-induced vibrations on a slider. Journal of Sound and Vibration, vol. 306, no. 3-5, p. 732-750, Dol:10.1016/j. jsv.2007.06.036.

[19] Yang, H.-J., Hu, Y., Chen, G.-X., Zhang, W.-H., Wu, G.-N. (2014). Correlation between the wear and vibration of the contact strip 
in a contact wire rubbing against a contact strip with electrical current. Tribology Transactions, vol. 57, no. 1, p. 86-93, DOI:10.1080/10402004.2013.850565.

[20] Bryant, M.D., York, D. (1999). Measurements and correlations of slider vibrations and wear. Journal of Tribology of the ASME, vol. 122, no. 1, p. 374-380, D0l:10.1115/1.555363.

[21] Deeva, V.S., Slobodyan, S.M. (2015). Dynamics of electrical conduction field of the sliding current collector. Applied Mechanics and Materials, vol. 698, p. 258-263, D0l:10.4028/ www.scientific.net/AMM.698.258.

[22] Kuz'mina, I.V., Rodionov, N.V., Rasskazova, E.G. (1995). Effect of heating on the behavior of copper-graphite composites with a binder. Powder Metallurgy and Metal Ceramics, vol. 33, no. 3-4, p. 165-167, DOI:10.1007/BF00559777.

[23] Jahanmard, P., Shojaei, A. (2015). Mechanical properties and structure of solvent processed novolac resin/layered silicate: development of interphase region. RSC Advances, vol. 5, p. 80875-80883, D0I:10.1039/C5RA12458A.

[24] Wang, Y., Lapovok, R., Wang, J.T., Estrin, Y. (2015). Effect of back pressure on the thermal stability of severely deformed copper. IOP Conference Series: Materials Science and Engineering: A, vol. 63, p. 1-10, Dol:10.1088/1757899X/63/1/012168.

[25] Lu, C.-T., Bryant, M.D. (1994). Thermoelastic evolution of contact area and mound temperatures in carbon graphite electrical brushes. Wear, vol. 174, no. 1-2, p. 137-146, Dol:10.1016/0043-1648(94)90095-7.

[26] Turel, A., Slavič, J., Boltežar, M. (2017). Electrical contact resistance and wear of a dynamically excited metal-graphite brush. Advances in Mechanical Engineering, vol. 9, no. 3, p. 1-8, Dol:10.1177/1687814017694801.

[27] Maia, N.M.M., Silva, J.M.M. (eds.) (1997). Theoretical and Experimental Modal Analysis. Engineering dynamics series. Research Studies Press.

[28] ISO/TC 164/SC 3 (2016). Hardness testing. ISO 65081:2016 - Metallic materials - Rockwell hardness test - Part 1: Test method. International Organization for Standardization, Geneva.

[29] Dean, J.A. (1995). Analytical Chemistry Handbook. McGrawHill Companies, New York.

[30] Shabadi, R., Avettand-Fenoel, M.N., Simar, A., Taillard, R., Jain, P.K., Johnson, R. (2015). Thermal conductivity in yttria dispersed copper. Materials \& Design, vol. 65, p. 869-877, D0l:10.1016/j.matdes.2014.09.083.

[31] Archard, J.F. (1953). Contact and rubbing of flat surfaces. Journal of Applied Physics, vol. 24, no. 8, p. 981-988, DOl:10.1063/1.1721448.

[32] Wriggers, P. (2006). Computational Contact Mechanics, 2nd ed. Springer-Verlag, Berlin, Heidelberg.

[33] Gyimah, G.K., Chen, D., Huang, P. (2013). Dry sliding studies of porosity on sintered Cu-based brake materials. Transaction on Control and Mechanical Systems, vol. 2, no. 5, p. 219-224.

[34] Queipo, P., Granda, M., Santamaría, R., R. Menéndez (2004). Preparation of pitch-based carbon-copper composites for electrical applications. Fuel, vol. 83, no. 11, p. 1625-1634, DOI:10.1016/j.fuel.2004.02.014. 